\title{
IMPACTO DO TRABALHO \\ INFANTOJUVENIL NO DESEMPENHO ESCOLAR PARA O BRASIL URBANO
}

(D) TAÍSE FÁTIMA MATTEI'

(D) MARINA SILVA DA CUNHA"

I Instituto Federal do Paraná, Palmas-PR, Brasil; taise_mattei_slo@hotmail.com

II Universidade Estadual de Maringá, Maringá-PR, Brasil; mscunha@uem.br

\section{RESUMO}

Este artigo avalia o impacto do trabalho infantojuvenil no desempenho escolar, utilizando como base de dados o Saeb de 2017 para alunos do $5^{\circ}$ e $9^{\circ}$ anos do ensino fundamental e do $3^{\circ}$ ano do ensino médio, com estratificações por regiões geográficas e gênero, e como estratégia de estimação o Propensity Score Matching. Constatou-se que o trabalho infantojuvenil afetou mais negativamente as notas de Português do que as de Matemática; seu impacto negativo sobre o desempenho escolar foi maior em alunos do $5^{\circ}$ ano, indicando ser mais prejudicial nos primeiros anos; e seu efeito negativo foi similar entre as regiões, sendo menor o desempenho escolar no Norte e Nordeste. As evidências sugerem, assim, que o trabalho infantojuvenil ainda é uma realidade no Brasil e pode prejudicar os investimentos em capital humano.

PALAVRAS-ChAVE TRABALHO INFANTIL • AVALIAÇÃO • PROPENSITY SCORE MATCHING • IMPACTO SOCIAL. 


\section{IMPACTO DEL TRABAJO DE NIÑOS Y JÓVENES EN EL DESEMPEÑO ESCOLAR PARA EL BRASIL URBANO}

\section{RESUMEN}

Este artículo pretende evaluar el impacto del trabajo de niños y jóvenes en el desempeño escolar, utilizando como base de datos el Saeb de 2017 para alumnos del $5^{\circ}$ al $9^{\circ}$ años de la educación básica y del $3^{\circ}$ año de la educación media, con estratificaciones por regiones geográficas y género, y como estrategia de estimación el Propensity Score Matching. Los resultados revelan que el trabajo afectó de forma más negativa las notas de Portugués que las de Matemáticas; el impacto negativo del trabajo sobre el desempeño escolar de los alumnos de $5^{\circ}$ año fue mayor, indicando que el trabajo es más perjudicial los primeros años, y que su efecto negativo fue similar entre las regiones, siendo menor el desempeño escolar en las regiones norte y noreste. De este modo, las evidencias sugieren que el trabajo de niños y jóvenes todavía es una realidad en Brasil y puede perjudicar las inversiones en capital humano.

PALABRAS CLAVE TRABAJO INFANTIL • EVALUACIÓN • PROPENSITY SCORE MATCHING • IMPACTO SOCIAL.

\section{IMPACT OF CHILD-YOUTH LABOR ON SCHOOL PERFORMANCE FOR URBAN BRAZIL}

\section{ABSTRACT}

This article assesses the impact of child and youth labor on school performance, using data from the 2017 SAEB for students in the 5th and 9th years of elementary school and the 3rd year of high school. The data were stratified by geographic regions and by gender, and used Propensity Score Matching as an estimation strategy. Reports indicate that child and youth labor affected grades in Portuguese more negatively than in mathematics. The negative impact was greater on the school performance of 5th year students, indicating that working is more harmful in the early years. In addition, the negative effect of child and youth labor was similar across all regions, although school performance is lower in the North and Northeast. Thus, the evidence suggests that child and youth labor is still a reality in Brazil and that it can undermine investments in human capital.

KEYWORDS CHILD LABOR • EVALUATION • PROPENSITY SCORE MATCHING • SOCIAL IMPACT. 


\section{INTRODUÇÃO}

A literatura sobre trabalho infantil e suas consequências para a educação, atraso e saúde das crianças, segundo Kassouf (2007), iniciou-se a partir do começo dos anos 1990 e tem se ampliado em razão de sua importância para o processo de desenvolvimento econômico e social. Cavaliere (2002) afirma que esse fenômeno não é recente, pois o trabalho infantil foi amplamente utilizado na Europa e em outras partes do mundo principalmente a partir da Revolução Industrial e, recentemente, encontra-se mais presente nos países em desenvolvimento.

É bastante discutida na literatura a definição de trabalho infantil, já que esse é um conceito que depende de aspectos legais, sociais e culturais, podendo variar entre os países. No Brasil, a idade mínima para se ingressar no mercado de trabalho é de 16 anos, exceto na condição de menor aprendiz, possível a partir dos 14 anos. Para os adolescentes de 16 a 18 anos são proibidos trabalhos insalubres, perigosos ou penosos, o trabalho noturno, os trabalhos que envolvam cargas pesadas e jornadas longas (BRASIL, 1988). Os limites de idade para qualificar crianças e jovens também geram debates. No Brasil, segundo o Estatuto da Criança e do Adolescente (ECA), criança é a pessoa que ainda não completou 12 anos, enquanto adolescente se enquadra na faixa etária entre 12 e 18 anos (BRASIL, 1990).

Ao longo do processo de desenvolvimento da literatura sobre o tema, várias medidas foram usadas para captar o desempenho escolar. Há pesquisadores que utilizam medidas de frequência escolar, reprovação, atraso escolar, entre outras. No entanto, atualmente as mais utilizadas são notas de testes, em geral proficiências e provas em diversas áreas, como Língua Portuguesa e Matemática (KASSOUF, 2007). Embora existam diferentes medidas, grande parte da literatura afirma que o trabalho infantil é um problema porque prejudica o desenvolvimento intelectual das crianças. O trabalho da criança, enquanto satisfaz as necessidades de renda presente para a família, compromete o desenvolvimento da vida futura da criança, na medida em que reduz o capital humano. No entanto, o trabalho para jovens e adolescentes não necessariamente é visto assim, uma vez que pode desenvolver habilidades como disciplina, responsabilidade, socialização, entre outros (CAVALIERI, 2002).

No Brasil, ainda há um número expressivo de crianças e adolescentes que trabalham. Segundo dados da Pesquisa Nacional por Amostra de Domicílios (Pnad) de 2015, das crianças de 5 a 9 anos, 0,55\% afirmou ter trabalhado na semana de referência. Na faixa etária de 10 a 17 anos, cerca de 10\% dessas crianças e adolescentes declararam ter trabalhado no mesmo período (BRASIL, 2015). Dessa forma, o problema da pesquisa é: crianças e adolescentes que trabalham fora de casa apresentam piora no seu desempenho escolar? A hipótese central é de que crianças e jovens que trabalham têm desempenho escolar inferior àquelas que não trabalham. 
Portanto, o objetivo geral deste artigo é avaliar o impacto do trabalho de crianças e adolescentes no desempenho escolar medido por meio das notas de proficiência em testes de Português e Matemática da Prova Brasil/Avaliação Nacional da Educação Básica (Aneb) de 2017. Embora a maioria dos estudos trate o trabalho de crianças como homogêneo, há diferenças de gênero, setores de atividades, entre outros. Ademais, o presente estudo discute essa temática não só para o Brasil urbano, mas também segundo as regiões geográficas, além de buscar captar as heterogeneidades de gênero entre as regiões brasileiras. São analisados alunos do $5^{\circ}$ e $9^{\circ}$ anos do ensino fundamental e da $3^{\mathrm{a}}$ série do ensino médio.

Assim, apesar da vasta literatura empírica sobre a temática no Brasil, neste trabalho se busca, por meio de informações mais recentes, verificar se ainda há efeitos significativos do trabalho para o desempenho de crianças e adolescentes no Brasil urbano e, além disso, analisar se existem diferenças regionais e de gênero. A escolha do Brasil urbano se justifica pelo fato de que o trabalho na área rural muitas vezes é realizado na unidade familiar, não sendo captado adequadamente por meio da variável disponível da Prova Brasil, que se refere ao trabalho fora do domicílio.

Além desta introdução, que apresenta os objetivos da pesquisa, o trabalho está organizado em mais cinco seções. A segunda aborda uma discussão sobre os determinantes do desempenho educacional; a terceira, por sua vez, discute os fatores que levam ao trabalho infantojuvenil. A quarta seção trata da metodologia, da base de dados e do procedimento Propensity Score Matching (PSM), utilizado para avaliação de impacto, ou seja, do trabalho infantil no desempenho escolar. Na quinta são apresentados e discutidos os resultados do trabalho; e, por fim, na última, estão as principais conclusões da pesquisa.

\section{DESEMPENHO EDUCACIONAL}

Barros et al. (2001) afirmam que o Brasil apresenta indicadores educacionais abaixo dos padrões internacionais, principalmente quando se analisa o nível de capital humano. Além disso, é preocupante o fato de que esses indicadores são piores para as pessoas mais pobres, levando em última instância à transmissão intergeracional da pobreza. Menezes-Filho (2007) corrobora tais afirmações apontando que o Brasil, após os anos 1990, elevou significativamente a frequência escolar em todos os níveis, no entanto, o desafio seria melhorar a qualidade da educação.

Na literatura são abordados vários fatores responsáveis pelo desempenho educacional brasileiro. Barros et al. (2001) apontam que a disponibilidade e qualidade dos serviços educacionais, a atratividade do mercado de trabalho local, a escassez de recursos familiares (financeiros e não financeiros) e o volume de recursos da comunidade em que o indivíduo vive são responsáveis por determinar a escolarização. 
Segundo os autores, quanto maiores a disponibilidade e qualidade dos serviços educacionais, bem como os recursos familiares e da comunidade em que o indivíduo está inserido, maior deve ser o nível educacional. Por outro lado, quanto mais atraentes as opções de trabalho para as pessoas que estudam, menores serão as probabilidades de continuar com a escolarização.

Para Menezes-Filho (2007) há alguns fatores associados ao desempenho escolar dos alunos. Assim, o desempenho escolar seria afetado por características da família e do aluno, tais como educação da mãe, cor, atraso escolar e reprovação, número de livros, presença de computador em casa e trabalho fora de casa. Ademais, em geral, os meninos têm desempenho em Matemática superior ao das meninas em todas as séries e as meninas têm desempenho melhor em Língua Portuguesa. Os alunos brancos tendem a apresentar desempenho superior ao dos negros e os alunos que estão atrasados ou foram reprovados mostram desempenho muito inferior ao daqueles que estão na série correta ou adiantados.

Segundo Colombo (2012), o aumento do número de computadores e de salas de aula, assim como a frequência escolar, melhora o desempenho na escola. Já para Menezes-Filho (2007), as variáveis no âmbito da escola, como número de computadores, escolaridade, idade e salário dos professores, têm efeitos pouco expressivos sobre o desempenho dos alunos. Uma das poucas variáveis nesse campo que afetam positivamente o desempenho do aluno é o número de horas-aula que ele permanece na escola. Além disso, indivíduos que estudam em escolas privadas tendem a apresentar desempenho melhor do que os alunos das escolas públicas. Quem participou da pré-escola tem, em todas as séries, desempenho superior ao dos alunos que entraram na escola a partir do $1^{\circ}$ ano do ensino fundamental.

A escolaridade dos pais é um fator fundamental para o nível educacional dos filhos e, segundo Barros et al. (2001), quanto mais elevada, maior é a renda familiar e tende a ser menor a dificuldade do custo de aprendizagem dos filhos. Para Menezes-Filho (2007), além da escolarização dos pais e, especificamente, da mãe, os alunos que moram com os pais, ou com pelo menos um deles, também têm tendência a apresentar desempenho melhor. Por outro lado, os que trabalham dentro de casa mais do que 4 horas por dia ou que trabalham fora apresentam desempenho pior. Existem ainda fatores não observados e difíceis de mensurar dos alunos e das escolas, que podem ser responsáveis pela melhora no desempenho escolar. Esses fatores podem ser esforço, dedicação, motivação, inteligência e facilidade de aprendizado do aluno, competência do diretor na gestão e motivação dos professores.

Assim, são vários os aspectos que podem afetar o desempenho escolar de crianças e adolescentes, desde características familiares até fatores econômicos e sociais. De toda forma, seria importante que crianças e jovens permanecessem o maior tempo possível na escola, a fim de ampliar sua formação e capital humano. 


\section{TRABALHO DE CRIANÇAS E ADOLESCENTES: CAUSAS E CONSEQUÊNCIAS}

Segundo Cavalieri (2002), do ponto de vista teórico, o impacto do trabalho sobre o desempenho escolar é ambíguo. Por um lado, o trabalho pode reduzir o tempo do indivíduo para o lazer e as atividades de aprendizagem, afetando o desempenho atual na escola e o futuro na vida profissional. Mas, por outro lado, pode aumentar a renda familiar e o investimento em educação no presente, promovendo o desenvolvimento de habilidades como disciplina, responsabilidade e socialização, entre outras que afetariam positivamente o desempenho escolar. No entanto, existe grande debate sobre as condições de trabalho e idades mínimas para que fosse socialmente aceitável, além de discussões sobre até que ponto os efeitos benéficos do trabalho sobressairiam aos efeitos negativos no desempenho escolar. Além disso, o trabalho não é o único fator para que crianças e adolescentes não frequentem a escola, embora seja possível que afete negativamente seu desempenho, aumentando a probabilidade de evasão e repetência.

Para Schwartzman e Schwartzman (2004), em geral, o trabalho tem efeito prejudicial no desenvolvimento da educação das crianças e dos adolescentes. Contudo, esse efeito depende de idade, tipo e duração do trabalho, e pode afetar tanto a presença na escola como o desempenho escolar. Porém, nem sempre é o trabalho que impacta o nível educacional. É bastante provável que a falta de escolas e as más condições de ensino tornem o trabalho uma opção mais atraente para os alunos, na medida em que traz benefícios monetários imediatos, apesar de levá-los à evasão e ao pior rendimento na escola. Mesmo que no Brasil a oferta educacional tenha se expandido e melhorado em comparação a anos passados, ainda existem situações precárias, principalmente em regiões mais pobres e zonas rurais. Alves-Mazzotti (2002) confirma, dizendo que os efeitos do trabalho infantojuvenil muitas vezes encobrem a atuação de outros fatores como carência de boas escolas, conteúdos distantes da realidade e falta de perspectiva de continuar os estudos. Colombo (2012), por sua vez, afirma que o trabalho é necessário, desde que não prejudique o desenvolvimento do indivíduo, principalmente entre as idades de 13 e 15 anos.

Segundo Kassouf (2007), existem elementos primordiais para explicar o trabalho de crianças e adolescentes, tais como: pobreza; escolaridade dos pais; tamanho e estrutura da família; sexo do chefe; idade em que os pais começaram a trabalhar; local de residência; entre outros. Para Alves-Mazzotti (2002), outras razões como autoafirmação, independência econômica e ideologia familiar também levam os adolescentes a procurar trabalho.

Schwartzman e Schwartzman (2004) também apontam alguns fatores determinantes para o trabalho de crianças e jovens no Brasil, tais como as características da família, o tipo de atividade, a ocupação e a posição na ocupação dos pais e onde eles vivem. Segundo os autores, não necessariamente o trabalho das crianças e 
jovens serve para complementar a renda familiar, embora isso aconteça em muitos casos. O trabalho em algumas situações contribui pouco para a renda familiar e outros elementos do contexto familiar podem ter mais importância. No entanto, o trabalho de crianças que pertencem a famílias com nível de renda baixo pode ter grande relevância. A baixa renda tende a aumentar o trabalho de crianças entre 10 e 14 anos, mas o trabalho de jovens nem sempre acontece devido à condição de renda baixa da família.

Além da renda familiar, viver com os dois pais ou só com a mãe não parece alterar o trabalho infantil de forma relevante. Porém, quando o pai e, principalmente, a mãe trabalham, a probabilidade de que os filhos também trabalhem é maior. Várias pesquisas mostram uma relação inversa do nível de escolaridade dos pais com o trabalho das crianças, sendo o efeito da escolaridade da mãe superior ao observado para a escolaridade do pai. O trabalho de Putnick e Bornstein (2015) confirmou que cuidadores com níveis mais altos de educação geravam menores probabilidades de as crianças se envolverem em todas as formas de trabalho infantil, seja dentro ou fora de casa. Dessa forma, quanto maior a escolaridade dos pais, principalmente a da mãe, menor a probabilidade de os filhos trabalharem. O tamanho da família geralmente também tem impacto no trabalho infantojuvenil. Muitas crianças trabalham mais quanto maior é o número de irmãos, principalmente mais novos, ou quanto maior é o número de membros da família (SCHWARTZMAN; SCHWARTZMAN, 2004; KASSOUF, 2007).

Em relação à cor ou raça, os grupos majoritários de brancos, pretos e pardos mostram níveis semelhantes de trabalho infantil, enquanto os dois grupos minoritários, de indígenas e orientais, apresentam resultados extremos e discrepantes. O efeito da idade da criança sobre sua probabilidade de trabalhar é na maioria dos casos positivo ou irrelevante. Rosati e Rossi (2003), em seu estudo sobre Paquistão e Nicarágua, concluem que crianças mais velhas podem ter maior probabilidade de abandono escolar para iniciarem uma atividade laboral.

A maioria dos estudos que incluem o sexo do responsável pela família infere que crianças de família chefiada por mulher têm maior probabilidade de trabalhar. Como a população do Brasil é em sua maioria urbana, o trabalho infantojuvenil tende a ocorrer também nas áreas urbanas, mas, em geral, tem mais importância nas regiões agrícolas, em atividades também agrícolas e em famílias que trabalham por conta própria, seja na agricultura ou em atividades urbanas. Em termos regionais, ele tende a preponderar tanto nos estados mais pobres do país como nos estados do Sul, que têm uma tradição de agricultura familiar mais consolidada (SCHWARTZMAN; SCHWARTZMAN, 2004; KASSOUF, 2007).

De fato, não existe um consenso na literatura sobre as consequências do trabalho infantojuvenil. No entanto, a maioria dos trabalhos assinala que quanto mais cedo 
o indivíduo começa a trabalhar, menor será seu salário na fase adulta. Em muitos trabalhos se verifica uma relação de mesmo sentido entre trabalho infantil e evasão escolar, reprovação, desempenho insatisfatório nas avaliações escolares, prejuízos para leitura e compreensão de texto, além de consequências para o estado de saúde da pessoa, tanto na infância como na fase adulta, e para os salários futuros.

Putnick e Bornstein (2015), por exemplo, encontraram relação de sentido oposto entre trabalho infantil e matrículas escolares de pessoas de baixa e média renda em um estudo que envolveu países como Bangladesh, Gana, Nigéria, Iraque, entre outros. Mesmo não sendo atividades mutuamente exclusivas, crianças em situação de trabalho foram menos propensas a estarem matriculadas em escola. Além disso, a associação de sentido contrário com a matrícula foi mais consistente para o trabalho familiar e tarefas domésticas do que para o trabalho fora de casa.

Emerson, Ponczek e Souza (2014) afirmam que crianças que trabalham enquanto frequentam a escola sofrem grande efeito negativo no progresso da aprendizagem. Seu estudo avaliou o impacto do trabalho sobre a aprendizagem medida pela proficiência de alunos no município de São Paulo por meio de seu desempenho em exames padronizados.

Muitos autores também atribuem ao trabalho infantil um impedimento para o desenvolvimento econômico de um país (BEZERRA; KASSOUF; ARENDS-KUENNING, 2009; KASSOUF, 2007; ALVES-MAZZOTTI, 2002). Kassouf (2007, p. 344) relata ainda que "a baixa escolaridade e o pior desempenho escolar, causados pelo trabalho infantil, têm o efeito de limitar as oportunidades de emprego [...] mantendo o jovem dentro de um ciclo repetitivo de pobreza”. Segundo Jacinto e Rodeghiero (2012), o sucesso no mercado de trabalho está diretamente ligado ao nível de escolaridade, e o trabalho pode acabar impedindo a aquisição de anos de escolaridade.

\section{METODOLOGIA}

Esta parte do trabalho tem por objetivo apresentar a abordagem empregada para estimar o impacto do trabalho infantojuvenil no desempenho escolar, ou seja, o Propensity Score Matching, além da base de dados e das variáveis utilizadas.

\section{Base de dados}

A base de dados utilizada na pesquisa são os microdados do Sistema de Avaliação da Educação Básica (Saeb) do ano de 2017 para a Prova Brasil/Aneb. ${ }^{1}$ Esses dados são disponibilizados pelo Instituto Nacional de Estudos e Pesquisas Educacionais Anísio Teixeira (Inep), que é uma autarquia federal vinculada ao Ministério da 
Educação (MEC). O Saeb foi aplicado pela primeira vez em 1990 e, atualmente, tem periodicidade de dois anos (BRASIL, 2017).

As informações do Saeb utilizadas abrangem alunos do $5^{\circ}$ e $9^{\circ}$ anos do ensino fundamental e $3^{\mathrm{a}}$ série do ensino médio. Para os três conjuntos de dados foram retirados aqueles indivíduos com informações sem resposta nos questionários socioeconômicos e foram feitas estratificações para as regiões geográficas Norte, Nordeste, Centro-Oeste, Sudeste e Sul. Além disso, para cada região foram feitas subdivisões entre gênero. A Tabela 1 apresenta a divisão da amostra do Brasil urbano em regiões segundo o gênero, bem como o percentual de alunos que informaram trabalhar fora de casa.

É possível perceber que as regiões Nordeste e Sudeste são as que apresentam maior número de observações e sobre as quais há mais informações disponíveis de alunos do ensino fundamental do que do ensino médio. As mulheres são maioria em todas as regiões entre alunos do $9^{\circ}$ ano do ensino fundamental e da $3^{\mathrm{a}}$ série do ensino médio.

TABELA 1 - Estratificação da amostra da base de dados do Brasil urbano em 2017 com indicação do percentual de alunos que declararam trabalhar fora de casa

\begin{tabular}{|c|c|c|c|c|c|c|c|c|c|}
\hline \multirow[t]{2}{*}{ REGIÕES } & \multicolumn{3}{|c|}{$\begin{array}{l}5^{\circ} \text { ANO ENSINO } \\
\text { FUNDAMENTAL }\end{array}$} & \multicolumn{3}{|c|}{$\begin{array}{l}9^{\circ} \text { ANO ENSINO } \\
\text { FUNDAMENTAL }\end{array}$} & \multicolumn{3}{|c|}{$3^{\circ}$ ANO ENSINO MÉDIO } \\
\hline & HOMEM & MULHER & TOTAL & HOMEM & MULHER & TOTAL & HOMEM & MULHER & TOTAL \\
\hline \multirow{2}{*}{ Norte } & 25.198 & 25.461 & 50.659 & 18.317 & 21.188 & 39.505 & 13.860 & 17.664 & 31.524 \\
\hline & $19,51 \%$ & $9,06 \%$ & $14,26 \%$ & $17,90 \%$ & $7,82 \%$ & $12,49 \%$ & $26,69 \%$ & $14,78 \%$ & $20,02 \%$ \\
\hline \multirow{2}{*}{ Nordeste } & 56.405 & 52.411 & 108.816 & 49.714 & 58.282 & 107.996 & 50.482 & 68.899 & 119.381 \\
\hline & $21,67 \%$ & $9,65 \%$ & $15,88 \%$ & $16,27 \%$ & $6,11 \%$ & $10,79 \%$ & $23,82 \%$ & $13,36 \%$ & $17,78 \%$ \\
\hline \multirow{2}{*}{ Centro-Oeste } & 17.863 & 17.553 & 35.416 & 16.755 & 18.311 & 35.066 & 10.501 & 13.631 & 24.132 \\
\hline & $15,20 \%$ & $6,48 \%$ & $10,88 \%$ & $23,68 \%$ & $11,00 \%$ & $17,06 \%$ & $44,36 \%$ & $27,63 \%$ & $34,91 \%$ \\
\hline \multirow{2}{*}{ Sudeste } & 90.126 & 88.671 & 178.797 & 78.075 & 84.492 & 162.567 & 66.704 & 84.477 & 151.181 \\
\hline & $13,69 \%$ & $5,86 \%$ & $9,80 \%$ & $17,71 \%$ & $8,42 \%$ & $12,89 \%$ & $36,63 \%$ & $25,55 \%$ & $30,44 \%$ \\
\hline \multirow{2}{*}{ Sul } & 32.214 & 31.458 & 63.672 & 29.901 & 33.754 & 63.655 & 13.519 & 16.755 & 30.274 \\
\hline & $12,32 \%$ & $5,31 \%$ & $8,86 \%$ & $22,60 \%$ & $12,21 \%$ & $17,09 \%$ & $46,04 \%$ & $33,52 \%$ & $39,11 \%$ \\
\hline
\end{tabular}

Fonte: Elaboração das autoras com base nos dados do Saeb 2017 (BRASIL, 2017).

No $5^{\circ}$ ano do ensino fundamental, há mais meninos que trabalham fora de casa do que meninas, e as maiores incidências estão nas regiões Norte e Nordeste. Já no $9^{\circ}$ ano do ensino fundamental os meninos ainda são a maioria dos alunos que trabalham fora, mas as maiores incidências são no Sul e no Centro-Oeste. No ensino médio, há uma proporção mais elevada de alunos que trabalham fora, sendo que a maioria detes estão nas regiões Sul e Centro-Oeste.

\section{Propensity Score Matching}

A análise mais correta para avaliar o impacto do trabalho de crianças e adolescentes sobre o desempenho escolar seria observar o desempenho dos alunos trabalhando 
e o desempenho dos mesmos alunos sem trabalhar. No entanto, como isso não é possível, a estratégia adotada se baseia no pareamento e na criação de um grupo de controle por meio do Propensity Score Matching, uma técnica proposta por Rosenbaum e Rubin (1983). O pareamento é feito por meio de características observadas (x), ou seja, estima-se uma regressão logit (ou probit) para determinar a probabilidade de cada aluno trabalhar com base em características observáveis. Com base nisso, gera-se um escore de propensão $(p(\mathbf{x}))$, que é utilizado para construir os grupos de comparação por meio de técnicas de pareamento. O matching consiste em escolher para cada indivíduo do grupo que trabalha um outro do grupo de controle, ou seja, que não trabalha, utilizando o escore de propensão (KHANDKER; KOOLWAL; SAMAD, 2009).

As variáveis utilizadas como controle na pesquisa estão descritas no Quadro 1, juntamente com os sinais esperados para a probabilidade de o aluno trabalhar fora de casa. Este trabalho levará em conta como controle não apenas as características dos alunos e de sua família, mas também informação da turma, da escola e dos professores, buscando uma análise mais robusta.

A variável dependente para aplicação do Propensity Score Matching é trabalha, para indicar se o aluno trabalhou fora de casa. No questionário socioeconômico do Saeb, é perguntado ao indivíduo se ele trabalha fora de casa, com ou sem remuneração, sendo possível a resposta sim ou não. Dessa forma, não há distinção entre trabalho perigoso, insalubre ou qualquer outro tipo, e não são considerados os afazeres domésticos que possam ser realizados pelos alunos dentro dos domicílios, ou o trabalho rural no ambiente familiar. Além disso, ressalta-se que os questionários socioeconômicos são respondidos pelos próprios alunos, sendo passíveis de omissão de variáveis e respostas incorretas e não verídicas.

$\mathrm{Na}$ base de dados não existe uma variável para a renda familiar do aluno, mas há perguntas do questionário socioeconômico a respeito da existência de bens como geladeira, banheiro, automóvel, computador e outros. Dessa forma, assim como em outros estudos, como em Ono (2015), por exemplo, é construída uma proxy para a renda baseada no Critério de Classificação Econômica do Brasil da Associação Brasileira de Empresas de Pesquisa (Abep), ${ }^{2}$ para o ano de 2014, visto que o questionário a partir de 2015 não é compatível com a base de dados de 2017 do Saeb. O critério para a definição da renda familiar é de pontos para cada item presente no domicílio e também para o grau de instrução do chefe da família. Neste estudo, foi considerado o grau de instrução da mãe em virtude de a maior parte das crianças e jovens afirmar morar com a mãe e devido à maior influência, em geral, que as mães têm no comportamento e nas decisões dos filhos.

2 As variáveis e rotinas usadas para a construção da proxy renda podem ser obtidas entrando em contato com as autoras. 


\section{QUADRO 1 - Variáveis e sinais esperados para a estimação do escore de propensão}

\begin{tabular}{|c|c|c|}
\hline VARIÁVEIS & DESCRIÇÃO & SINAL ESPERADO \\
\hline \multicolumn{3}{|c|}{ VARIÁVEL DEPENDENTE } \\
\hline Trabalha & 1- se o aluno trabalha fora de casa; 0 - caso contrário & Variável dependente \\
\hline \multicolumn{3}{|c|}{ VARIÁVEIS INDEPENDENTES REFERENTES AO ALUNO } \\
\hline Sexo & 1- homem; 0-mulher & Positivo \\
\hline Brancos & 1- brancos e amarelos; 0- pretos, pardos e indígenas & $\begin{array}{l}\text { Divergente com tendência } \\
\text { negativa }\end{array}$ \\
\hline Reprovado & 1- se o aluno já foi reprovado; 0 - caso contrário & Positivo \\
\hline Idade & Construída a partir de 2017 - (menos) ano de nascimento & Positivo \\
\hline Incentivo estudo & 1- se os pais incentivam a estudar; 0 - caso contrário & Negativo \\
\hline Incentivo escola & 1- se os pais incentivam ir para a escola; 0 - caso contrário & Negativo \\
\hline Estudo mãe & \multirow{2}{*}{$\begin{array}{l}\text { Nunca estudou ou não completou a } 4^{\mathrm{a}} \text { série } E F^{1}=0 ; \text { possui apenas } \\
\text { até a } 4^{\text {a }} \text { série } E F=4 ; \text { possui } E F \text { completo, mas não o } \mathrm{EM}^{2}=8 ; \\
\text { possui } E M \text { completo, mas não superior }=11 ; \text { possui ensino superior } \\
\text { completo ou pós-graduação }=15\end{array}$} & \multirow{2}{*}{ Negativo } \\
\hline Estudo pai & & \\
\hline Mora com pais & 1- se mora com os dois pais; 0 - caso contrário & $\begin{array}{l}\text { Negativo em relação a } \\
\text { morar com outras pessoas }\end{array}$ \\
\hline Mora só mãe & 1- se mora apenas com a mãe; 0 - caso contrário & $\begin{array}{l}\text { Negativo em relação a } \\
\text { morar com outras pessoas }\end{array}$ \\
\hline Mora só pai & 1- se mora apenas com o pai; 0 - caso contrário & $\begin{array}{l}\text { Negativo em relação a } \\
\text { morar com outras pessoas }\end{array}$ \\
\hline Pessoas & $\begin{array}{l}\text { Incluindo o aluno, pessoas que vivem atualmente na casa (varia de } 1 \\
\text { a } 6 \text {, sendo que no questionário pode ser } 6 \text { ou mais) }\end{array}$ & Positivo \\
\hline Manhã & 1- se estuda no turno da manhã; 0 - caso contrário & Negativo em relação à noite \\
\hline Tarde & 1- se estuda no turno da tarde; 0 - caso contrário & Negativo em relação à noite \\
\hline Proxy renda & $\begin{array}{l}\text { Valor renda média bruta mensal mensurado pelo critério de } \\
\text { classificação econômica da Abep (varia de } \mathrm{R} \$ 895 \text { a } \mathrm{R} \$ 11.097 \text { ) }\end{array}$ & $\begin{array}{l}\text { Divergente com tendência } \\
\text { negativa }\end{array}$ \\
\hline Atraso & $\begin{array}{l}\text { 1- se: idade }>11 \text { para } 5^{\circ} \text { ano } E F \text {; idade }>15 \text { para } 9^{\circ} \text { ano } E F \text {; idade }>18 \\
\text { para } 3^{\text {a }} \text { série } E M ; 0 \text { - caso contrário }\end{array}$ & Positivo \\
\hline \multicolumn{3}{|c|}{ VARIÁVEIS INDEPENDENTES REFERENTES À ESCOLA } \\
\hline $\begin{array}{l}\text { Acesso internet } \\
\text { alunos }\end{array}$ & $\begin{array}{l}\text { 1- para existência de acesso à internet para os alunos; } 0 \text { - caso } \\
\text { contrário }\end{array}$ & Negativo \\
\hline Conservação & $\begin{array}{l}\text { Estado de conservação da escola. Soma de pontos referentes aos } \\
\text { itens: telhado, parede, piso, entrada, pátio, corredor, salas, portas, } \\
\text { janelas, cozinha, banheiros, instalações elétricas e hidráulicas. 3- } \\
\text { bom, 2- regular, 1- ruim, 0- inexistente }\end{array}$ & Negativo \\
\hline \multicolumn{3}{|c|}{ VARIÁVEIS INDEPENDENTES REFERENTES AO PROFESSOR } \\
\hline Escolaridade prof. & $\begin{array}{l}\text { 0- EM incompleto; 1- EM completo; 2- superior; 3-aperfeiçoamento; } \\
\text { 4- especialização; } 5 \text { - mestrado; 6- doutorado. Média da escolaridade } \\
\text { dos professores por turma }\end{array}$ & Negativo \\
\hline Experiência prof. & $\begin{array}{l}\text { 1- } 1 \text { ano; } 1,5 \text { - entre } 1 \text { e } 2 \text { anos; } 4 \text { - entre } 3 \text { e } 5 \text { anos; } 8 \text { - entre } 6 \text { e } 10 \\
\text { anos; } 13 \text { - entre } 11 \text { e } 15 \text { anos; } 18 \text { - entre } 16 \text { e } 20 \text { anos; } 21 \text { - mais de } 20 \\
\text { anos. Média da experiência dos professores por turma }\end{array}$ & Negativo \\
\hline \multicolumn{3}{|c|}{ VARIÁVEIS INDEPENDENTES REFERENTES À TURMA } \\
\hline$N^{\circ}$ alunos turma & Contagem do número de alunos por turma & Divergente \\
\hline$\%$ meninos turma & Proporção de homens na turma & Divergente \\
\hline
\end{tabular}

Fonte: Elaboração das autoras com base nos dados do Saeb 2017 (BRASIL, 2017).

Nota: ${ }^{1} \mathrm{EF}$ : ensino fundamental; ${ }^{2} \mathrm{EM}$ : ensino médio.

Como variáveis de resultado, para medir o desempenho escolar, são utilizadas as notas padronizadas dos testes de proficiência em Língua Portuguesa e Matemática 
medidos em escala única pelo Saeb, com média 250 e desvio padrão 50, utilizados em logaritmo neste estudo.

Portanto, essa abordagem constrói dois grupos, tratamento e controle, que são semelhantes em todas as suas características (x), apenas diferindo em relação à variável de impacto, neste caso, se trabalha fora de casa ou não. Dessa forma, os tratados (grupo tratamento) são formados por alunos que trabalham fora de casa e os controles (grupo controle) são aqueles que não trabalham fora de casa, mas têm características similares aos tratados. O pareamento busca construir a região de suporte comum e criar o grupo de controle. As técnicas de pareamento utilizadas nesta pesquisa são: um vizinho mais próximo com reposição, na qual compara-se o escore do tratado com o do controle mais próximo e usa-se um escore do controle como vizinho de mais de um tratado; um vizinho mais próximo sem reposição, na qual escolhe-se o grupo de controle com base em um escore mais próximo, sendo que cada controle só é utilizado uma vez na comparação com tratados; cinco vizinhos mais próximos, na qual compara-se o escore do tratado com o dos cinco vizinhos mais próximos; kernel, na qual seleciona-se o grupo de controle comparando o escore de todos os tratados com várias observações, com base em uma distribuição kernel, em que o peso atribuído é inversamente proporcional à distância desses dois grupos; e raio, na qual define-se uma distância para achar os controles de cada tratamento, sendo que foi utilizado um caliper de 0,01, que é o valor base para a distância máxima tolerável entre os escores (KHANDKER; KOOLWAL; SAMAD, 2009).

Após a realização dos pareamentos, devem ser feitos testes de balanceamento entre os grupos de tratamento e controle. O balanceamento é obtido comparando-se as probabilidades dos tratados $(T=1)$ e não tratados $(T=0)$. Eles devem apresentar as mesmas probabilidades de estarem nos dois grupos. Para que o pareamento seja satisfatório, uma opção é realizar um teste $t$ de média para todas as variáveis do logit e também para o escore de propensão. A hipótese nula do teste é de que a diferença das médias é zero após o pareamento, ou seja, as médias dos dois grupos são iguais e os indivíduos são similares. Para que os grupos sejam balanceados, a hipótese nula de que os valores médios dos dois grupos não diferem após a correspondência não pode ser rejeitada para nenhuma variável (KHANDKER; KOOLWAL; SAMAD, 2009).

Além do teste $t$ de média, outros procedimentos podem ser realizados para se testar o balanceamento dos grupos de tratamento e controle, como uma análise visual da densidade de probabilidade dos dois grupos, uma análise do pseudo- $\mathrm{R}^{2}$ e do viés de seleção antes e depois do pareamento. Depois do pareamento os indivíduos devem apresentar densidades de probabilidade similares, e o $\mathrm{R}^{2}$, após se reestimar o escore de propensão utilizando apenas informações de tratados e controles, deve diminuir, indicando que o matching foi bem realizado. Caliendo e Kopeinig (2005) também afirmam que após a correspondência não deve haver diferenças sistemáticas 
na distribuição das covariáveis entre os dois grupos e, portanto, o pseudo- $\mathrm{R}^{2}$ deveria estar relativamente baixo. Já o viés refere-se à diferença dos valores médios do grupo de tratamento e do grupo de não tratamento, dividida pela raiz quadrada da variância média da amostra no grupo de tratamento e pelo grupo de tratamento não pareado. Para Caliendo e Kopeinig (2005), uma redução de viés abaixo de 3\% ou 5\% é tida como suficiente.

Por fim, o que se pretende estimar, após os pareamentos e testes de balanceamento, é o efeito médio do tratamento (ATT), isto é, o impacto do trabalho no desempenho dos alunos, por meio de notas de proficiência em Português e Matemática $\left(Y_{i}\right)$, que assume valor $Y_{1}$ caso o aluno receba o tratamento $\left(T_{j}=1\right)$ e $Y_{0}$ caso o aluno não receba o tratamento $\left(T_{j}=0\right)$. Como não é possível observar o mesmo aluno nas duas condições, de tratado e de controle, trabalha-se com a esperança matemática. Assim, o ATT sobre os tratados é definido de acordo com a equação 1 .

$$
\mathrm{ATT}=\mathrm{E}_{p(\mathbf{x}) \mid T=1}\left\{\mathrm{E}\left[Y_{1} \mid \mathrm{T}=1, p(\mathrm{x})\right]-\mathrm{E}\left[Y_{0} \mid \mathrm{T}=0, p(\mathrm{x})\right]\right\}
$$

O ATT é identificado pela diferença da variável de resultado entre tratados e controles. Portanto, a hipótese nula de que não há diferença no resultado entre tratados e controles deve ser rejeitada para que a diferença seja estatisticamente significativa.

Assim, após a definição das variáveis e estimação do logit, é aplicada a técnica Propensity Score Matching. A primeira etapa do PSM consiste em estimar um modelo logit para a probabilidade de o aluno trabalhar fora de casa, com as variáveis especificadas e, a partir daí, gera-se o escore de propensão. Após isso, são aplicadas as técnicas de pareamento um vizinho, um vizinho sem reposição, cinco vizinhos, kernel e raio. As técnicas de pareamento servem para construir os grupos de tratamento e controle usando o escore de propensão, sendo que o objetivo é encontrar indivíduos parecidos nos dois grupos, diferenciando-se apenas pelo fato de os tratados pertencerem ao grupo de pessoas que trabalham fora de casa. Realizados os pareamentos, o próximo passo consiste em testar a sua adequação, ou seja, testar as condições de balanceamento. Por fim, após os testes e verificação de um bom pareamento, estima-se o efeito médio do tratamento sobre os tratados (ATT).

\section{APRESENTAÇÃO E ANÁLISE DOS DADOS}

\section{Pareamento e testes}

Esta parte do trabalho discute os resultados das etapas do PSM e os testes estatísticos para, posteriormente, analisar o impacto do trabalho das crianças e adolescentes no desempenho escolar. As estatísticas descritivas não foram apresentadas em função do espaço, mas podem ser obtidas em contato com as autoras. Na Tabela 
2 se observam as estimações da regressão logit, de todas as regiões geográficas e séries analisadas, para a probabilidade de os alunos trabalharem fora de casa.

Analisando primeiramente a estimação para o $5^{\mathrm{a}}$ ano do ensino fundamental, verifica-se que alunos homens, que já haviam sido reprovados alguma vez e mais velhos, tinham probabilidade maior de trabalharem fora de casa em todas as regiões, com significância estatística. Por outro lado, alunos que recebiam incentivos dos pais para estudar e ir à escola apresentavam probabilidade menor de trabalhar fora de casa. No mesmo sentido, quanto maior era o nível de escolaridade do pai e da mãe, menor era a probabilidade de os filhos exercerem alguma atividade laboral. Bezerra (2006) indica a importância da escolaridade dos pais para a redução do trabalho em idade escolar dos filhos, apontando que deveriam existir mais políticas públicas para ampliar o nível educacional no país.

Variáveis como ser branco e morar com ambos os pais, só com o pai ou só com a mãe apresentaram divergência no sinal nas regiões geográficas e, em alguns casos, não foram significativas. A renda média familiar apresentou significância estatística e sinal positivo, mas com magnitude insignificante.

$\mathrm{O}$ atraso escolar apresentou relação de mesmo sentido com o trabalho fora de casa em todas as regiões, conforme o esperado, exceto no Centro-Oeste. As características da escola, como acesso à internet para os alunos e conservação da escola, contribuíram para reduzir a probabilidade do trabalho na maioria das regiões. Além dessas, quanto maior a escolaridade dos professores e maior o número de alunos nas turmas, menores são as chances de os alunos ingressarem no mercado de trabalho. A proporção de meninos na turma e a experiência do professor não tiveram relação clara com o trabalho em idade escolar. 


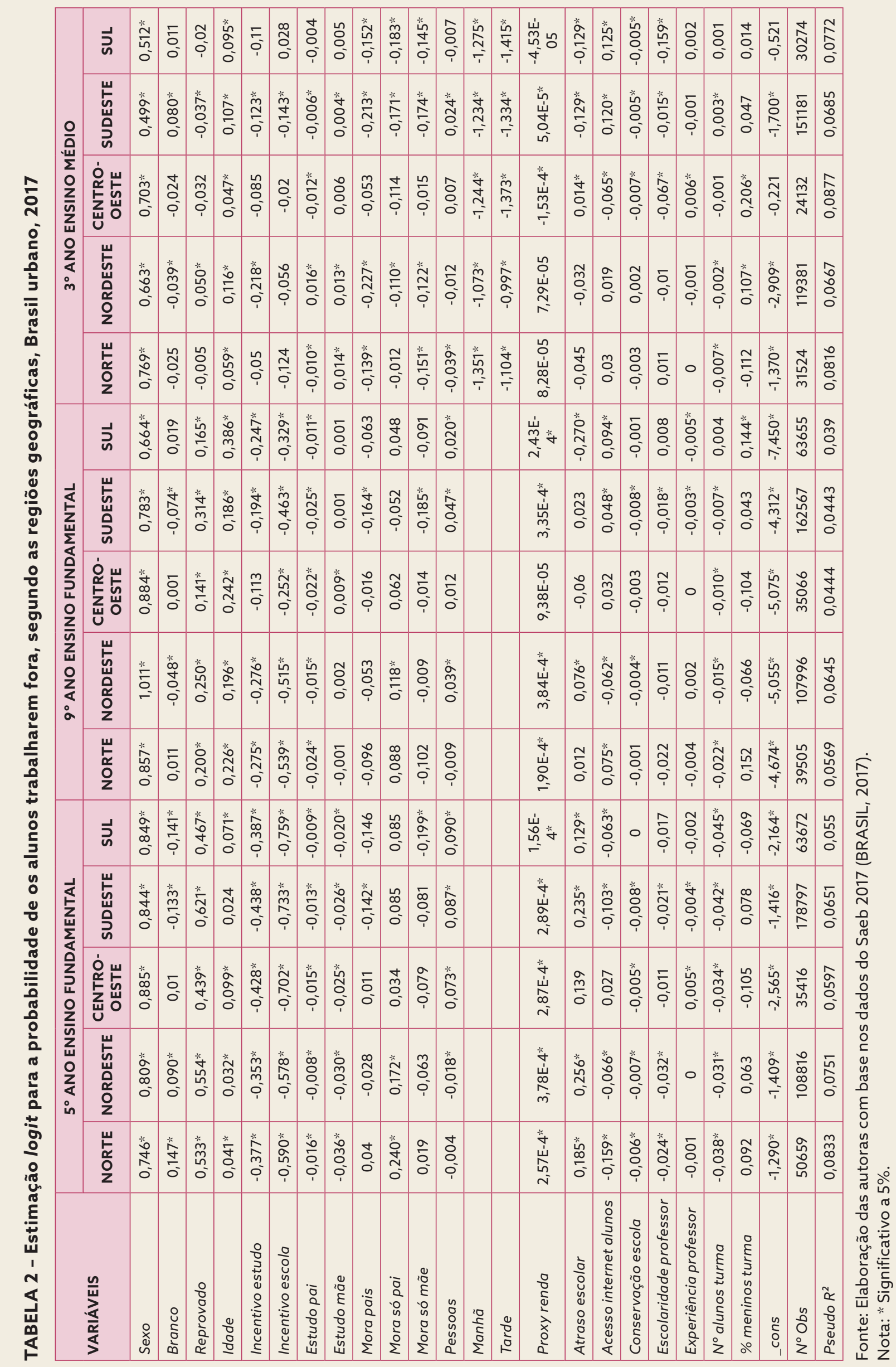


Para os alunos do $9^{\circ}$ ano do ensino fundamental, foi possível perceber que variáveis como sexo, ter sido reprovado e proxy da renda apresentaram relação de mesmo sentido e significativa para a probabilidade de o aluno trabalhar fora de casa, ressaltando que esta apresentou magnitude insignificante. As demais variáveis apresentaram relação de sentido oposto para a probabilidade de o aluno trabalhar, indicando que alunos brancos e que recebiam incentivos dos pais apresentavam probabilidade menor de trabalhar fora de casa. Além disso, a escolaridade dos pais e viver com ambos os pais ou apenas com a mãe também se mostraram importantes fatores para reduzir a probabilidade da atividade laboral das crianças.

$\mathrm{O}$ atraso escolar, o acesso à internet para os alunos, a experiência do professor, o número de alunos por turma e a proporção de meninos não apresentaram relação clara com a probabilidade do trabalho dos alunos. Por outro lado, a conservação da escola e a escolaridade do professor diminuíam a chance de os alunos trabalharem.

A última análise diz respeito aos alunos da $3^{\circ}$ série do ensino médio, em que se verifica que alunos do sexo masculino e que possuíam idade mais elevada apresentavam maiores chances de trabalhar. Alunos que estudavam nos turnos da manhã ou da tarde possuíam menores chances de trabalhar. Morar com ambos os pais, só com o pai ou só com a mãe reduzia a probabilidade do trabalho em algumas regiões; já o nível de escolaridade dos pais não mostrou tanta importância para evitar o trabalho em idade escolar de alunos do ensino médio.

Para os alunos do ensino médio, o atraso escolar pareceu ser importante para determinar a probabilidade de ingresso no mercado de trabalho, mas as variáveis de características da escola e dos professores não apresentaram relações claras para a atividade laboral.

Em todos os níveis de ensino analisados, os resultados foram parecidos com as análises de Putnick e Bornstein (2015). Segundo os autores, quanto maior a escolaridade dos pais, menores são as chances de as crianças trabalharem, e quanto maior a idade da criança, menor é a probabilidade de se envolver em atividade laboral. Além disso, para o trabalho infantil, trabalho familiar e tarefas domésticas excessivas, os países estavam divididos sobre o efeito de gênero, já que esses efeitos são provavelmente o resultado de relações complexas entre as normas de gênero de cada país. Os resultados também estão de acordo com Emerson, Ponczek e Souza (2014), que encontraram que o trabalho infantil afeta os alunos mais jovens mais do que os alunos mais velhos.

Embora se perceba que o pseudo- $\mathrm{R}^{2}$ foi baixo em todas as especificações, conforme Khandker, Koolwal e Samad (2009), essa metodologia busca encontrar bons grupos de comparação, ficando a análise qualitativa do logit em segundo plano. Ademais, quando se trata de microdados, esse critério de ajustamento apresenta valores mais baixos (GREENE, 2018). 
Após a estimação da regressão logit, geraram-se os escores de propensão e foram aplicadas as técnicas de pareamento um vizinho com e sem reposição, cinco vizinhos, kernel e raio. Ressalta-se que não existe na literatura indicação de qual técnica é melhor para o pareamento, no entanto, a maior parte dos trabalhos apresenta mais de uma técnica. Segundo Khandker, Koolwal e Samad (2009), cada técnica possui vantagens e desvantagens. Por exemplo, o pareamento de um vizinho descarta muitos controles, já o pareamento kernel maximiza o número de pares da região de suporte comum. Optou-se nesta parte do trabalho por cinco técnicas, buscando trazer maior robustez à pesquisa.

Como indicado na metodologia, após o pareamento, devem-se testar as condições de balanceamento. $\mathrm{O}$ balanceamento pode ser testado por meio da estatística $t$ de cada variável do logit e do escore de propensão, pelo teste do pseudo- $\mathrm{R}^{2}$, pela análise do viés e também pelo gráfico de distribuição de densidade. Neste artigo, em função do espaço, não foram apresentados os testes, mas todos eles foram realizados. ${ }^{3}$

Para o $5^{\circ}$ ano do ensino fundamental, o pseudo- $\mathrm{R}^{2}$ diminuiu após o pareamento em todas as técnicas aplicadas, exceto para kernel no Nordeste, Sudeste e Sul, mas o viés médio permaneceu menor que 5\% em todas as técnicas e regiões. Com relação ao $9^{\circ}$ ano do ensino fundamental, todas as técnicas em todas as regiões apresentaram viés médio dentro do limite após o pareamento. Já para a $3^{\mathrm{a}}$ série do ensino médio, o viés médio ficou dentro do limite para todas as especificações, em todas as regiões, exceto para um vizinho sem reposição, no Sul. Dessa forma, os grupos foram balanceados para estimar o efeito do trabalho de crianças e jovens no desempenho escolar.

\section{Impacto do trabalho infantojuvenil no desempenho escolar}

Após os testes de balanceamento foi possível estimar o impacto do trabalho de crianças e adolescentes no desempenho escolar, conforme a Tabela 3. Considerando os testes realizados, o ATT foi apresentado apenas para o pareamento raio, pois se mostrou satisfatório em todas as regiões. Duas variáveis de resultado foram analisadas: notas de proficiência de Português e notas de proficiência de Matemática.

Verifica-se que o impacto do trabalho no desempenho escolar em Português e Matemática de estudantes do $5^{\circ}$ ano do ensino fundamental foi significativo em todas as regiões geográficas. Na região Norte, o trabalho de crianças e adolescentes reduziu as notas de Português em 11,6\% e as de Matemática em 8\%. Na região Nordeste, reduziu as notas de Português em 13\% e as de Matemática em 9,8\%. Na

3 As análises do pseudo- $\mathrm{R}^{2}$, antes e depois do pareamento, e do percentual de viés, após o matching, o teste $t$ de balanceamento de cada variável do logit e a análise gráfica podem ser solicitadas às autoras se necessário. 
região Centro-Oeste, a redução em Português foi em torno de 11\% e em Matemática em cerca de $8 \%$. Nas regiões Sudeste e Sul, o trabalho afetou negativamente as notas de Português em torno de $12 \%$ e 10\%, respectivamente, e as de Matemática em torno de $9 \%$ e 7\%, respectivamente. Assim, em todas as regiões geográficas, o trabalho afetou mais as notas de Português do que as de Matemática.

TABELA 3 - Efeito do trabalho sobre o desempenho escolar segundo regiões geográficas, Brasil urbano, 2017

\begin{tabular}{|c|c|c|c|c|c|c|c|c|}
\hline \multirow{2}{*}{ REGIÕES } & \multicolumn{4}{|c|}{ PORTUGUÊS } & \multicolumn{4}{|c|}{ MATEMÁTICA } \\
\hline & TRATAMENTO & CONTROLE & ATT & $t$ & TRATAMENTO & CONTROLE & ATT & $t$ \\
\hline \multicolumn{9}{|c|}{$5^{\circ}$ ANO ENSINO FUNDAMENTAL } \\
\hline Norte & 5,135 & 5,251 & $-0,116$ & $-37,84^{*}$ & 5,226 & 5,307 & $-0,081$ & $-28,90 *$ \\
\hline Nordeste & 5,108 & 5,239 & $-0,131$ & $-66,04 *$ & 5,203 & 5,301 & $-0,098$ & $-54,34$ \\
\hline Centro-Oeste & 5,243 & 5,355 & $-0,112$ & $-27,53^{*}$ & 5,323 & 5,405 & $-0,082$ & $-21,83^{*}$ \\
\hline Sudeste & 5,26 & 5,386 & $-0,126$ & $-65,66 *$ & 5,356 & 5,447 & $-0,091$ & $-51,73^{*}$ \\
\hline Sul & 5,281 & 5,382 & $-0,101$ & $-31,86^{*}$ & 5,372 & 5,444 & $-0,072$ & $-24,40$ \\
\hline \multicolumn{9}{|c|}{$9^{\circ}$ ANO ENSINO FUNDAMENTAL } \\
\hline Norte & 5,466 & 5,497 & $-0,031$ & $-10,15^{*}$ & 5,475 & 5,489 & $-0,014$ & $-4,65^{*}$ \\
\hline Nordeste & 5,44 & 5,483 & $-0,043$ & $-20,89 *$ & 5,464 & 5,488 & $-0,024$ & $-11,88^{*}$ \\
\hline Centro-Oeste & 5,531 & 5,563 & $-0,032$ & $-11,58 *$ & 5,551 & 5,566 & $-0,014$ & $-5,23 *$ \\
\hline Sudeste & 5,507 & 5,551 & $-0,044$ & $-28,62 *$ & 5,538 & 5,559 & $-0,021$ & $-14,09 *$ \\
\hline Sul & 5,554 & 5,579 & $-0,024$ & $-12,01 *$ & 5,584 & 5,59 & $-0,006$ & $-2,89 *$ \\
\hline \multicolumn{9}{|c|}{$3^{\text {a }}$ SÉRIE ENSINO MÉDIO } \\
\hline Norte & 5,492 & 5,503 & $-0,011$ & $-3,75^{*}$ & 5,506 & 5,507 & $-0,001$ & $-0,48$ \\
\hline Nordeste & 5,522 & 5,523 & $-0,001$ & $-0,71$ & 5,543 & 5,532 & 0,011 & $6,99 *$ \\
\hline Centro-Oeste & 5,567 & 5,594 & $-0,027$ & $-9,53^{*}$ & 5,591 & 5,602 & $-0,012$ & $-4,04 *$ \\
\hline Sudeste & 5,58 & 5,597 & $-0,017$ & $-14,98 *$ & 5,592 & 5,596 & $-0,003$ & $-2,85^{*}$ \\
\hline Sul & 5,578 & 5,598 & $-0,021$ & $-8,45^{*}$ & 5,604 & 5,609 & $-0,005$ & $-2,04 *$ \\
\hline
\end{tabular}

Fonte: Elaboração das autoras com base nos dados do Saeb 2017 (BRASIL, 2017).

Nota: * Significativo a $5 \%$.

Por sua vez, o desempenho escolar das crianças e jovens do $9^{\circ}$ ano do ensino fundamental teve impacto negativo e significativo para todas as notas em todas as regiões. Observa-se que a atividade laboral reduziu as notas de Português em torno de $4 \%$ nas regiões Norte, Nordeste, Centro-Oeste e Sudeste, e em torno de 2\% na região Sul. Já o trabalho reduziu as notas de Matemática em torno de $0,6 \%$ na região Sul e $2 \%$ nas demais regiões.

Mais uma vez se repetiu o padrão do maior impacto para notas de Português. Acredita-se que isso se deva ao fato de que a disciplina Língua Portuguesa requer maior atenção e concentração dos alunos, sendo mais afetada pela atividade laboral, o que pode levar à redução do rendimento dos alunos em sala de aula. Um estudo do Inep (BRASIL, 2003) usando dados do Saeb de 2001 revelou que, para alunos 
do $8^{\circ}$ ano do ensino fundamental, aqueles que não trabalhavam apresentavam 25 pontos a mais em Português e 21 pontos a mais em Matemática, em consonância com os resultados encontrados nesta pesquisa.

Por sua vez, para jovens da $3^{\text {a }}$ série do ensino médio, o impacto do trabalho nas notas de Português foi negativo e significativo em todas as regiões, exceto Nordeste, em aproximadamente $2 \%$ e, nas notas de Matemática, negativo e significativo apenas nas regiões Centro-Oeste, Sudeste e Sul. Somente no Nordeste os resultados sugerem que o trabalho melhora as notas de Matemática, com significância estatística. Isso pode ser explicado pelo fato de que adolescentes do ensino médio têm mais interesse na busca voluntária pelo trabalho para possibilitar a independência financeira, porque no Nordeste houve a menor proporção desses alunos em condição de trabalho fora do domicílio, ou ainda porque no Nordeste o desempenho escolar é baixo de modo geral.

Em geral, o impacto do trabalho na região Sul foi menor do que nas demais regiões para o ensino fundamental, enquanto no Centro-Oeste foi maior do que as demais para o ensino médio. Note-se que o efeito negativo no ensino fundamental nas regiões Nordeste e Sudeste é similar, em torno de 13\% em Português e 9\% em Matemática, nas séries iniciais, e cerca de $4 \%$ e $2 \%$, respectivamente, nas finais. Nesse sentido, não necessariamente as regiões tradicionalmente mais pobres foram as que apresentaram o maior impacto negativo nas notas. Pode-se observar também que o impacto do trabalho para jovens da $3^{\mathrm{a}}$ série do ensino médio foi bem menor do que para alunos do ensino fundamental, não ultrapassando redução de $3 \%$ nas notas de Português e 1\% nas de Matemática.

Adicionalmente, além da análise estratificada por regiões geográficas, é também apresentada uma divisão segundo o gênero e a localização, classificando em homem e mulher, para as três séries analisadas, denominada de heterogeneidades. Nessa estratificação foi usada a técnica de pareamento raio, cujos testes indicaram bom balanceamento dos grupos de tratamento e controle. A Tabela 4 apresenta o resultado do efeito do trabalho no desempenho escolar dos alunos das três séries analisadas, segundo as heterogeneidades regionais. 
TABELA 4 - Efeito médio do trabalho (ATT) sobre o desempenho escolar segundo heterogeneidades regionais, Brasil urbano, 2017

\begin{tabular}{|c|c|c|c|c|c|c|c|c|}
\hline \multirow{3}{*}{ REGIÕES } & \multicolumn{4}{|c|}{ PORTUGUÊS } & \multicolumn{4}{|c|}{ MATEMÁTICA } \\
\hline & \multicolumn{2}{|c|}{ HOMEM } & \multicolumn{2}{|c|}{ MULHER } & \multicolumn{2}{|c|}{ HOMEM } & \multicolumn{2}{|c|}{ MULHER } \\
\hline & ATT & $t$ & ATT & $\boldsymbol{t}$ & ATT & $t$ & ATT & $t$ \\
\hline \multicolumn{9}{|c|}{$5^{\circ}$ ANO ENSINO FUNDAMENTAL } \\
\hline Norte & $-0,104$ & $-27,40 *$ & $-0,141$ & $-26,35^{*}$ & $-0,071$ & $-20,28 *$ & $-0,097$ & $-21,04 *$ \\
\hline Nordeste & $-0,118$ & $-48,76^{*}$ & $-0,155$ & $-44,88 *$ & $-0,089$ & $-39,95^{*}$ & $-0,112$ & $-36,27 *$ \\
\hline Centro-Oeste & $-0,107$ & $-21,67 *$ & $-0,125$ & $-16,93^{*}$ & $-0,077$ & $-17,02 *$ & $-0,093$ & $-13,73^{*}$ \\
\hline Sudeste & $-0,121$ & $-52,63^{*}$ & $-0,135$ & $-38,27 *$ & $-0,086$ & $-40,40 *$ & $-0,098$ & $-31,23 *$ \\
\hline Sul & $-0,096$ & $-25,48 *$ & $-0,111$ & $-19,05^{*}$ & $-0,068$ & $-19,24 *$ & $-0,081$ & $-14,89 *$ \\
\hline \multicolumn{9}{|c|}{$9^{\circ}$ ANO ENSINO FUNDAMENTAL } \\
\hline Norte & $-0,04$ & $-10,13^{*}$ & $-0,018$ & $-3,68^{*}$ & $-0,021$ & $-5,37 *$ & $-0,001$ & $-0,3$ \\
\hline Nordeste & $-0,05$ & $-19,76^{*}$ & $-0,026$ & $-7,52 *$ & $-0,029$ & $-11,57^{*}$ & $-0,013$ & $-3,69 *$ \\
\hline Centro-Oeste & $-0,038$ & $-10,60 *$ & $-0,02$ & $-4,79 *$ & $-0,02$ & $-5,74^{*}$ & $-0,006$ & $-1,35$ \\
\hline Sudeste & $-0,055$ & $-27,71^{*}$ & $-0,025$ & $-10,73 *$ & $-0,031$ & $-15,83 *$ & $-0,005$ & $-2,05^{*}$ \\
\hline Sul & $-0,034$ & $-12,40 *$ & $-0,009$ & $-3,23 *$ & $-0,014$ & $-5,44^{*}$ & 0,005 & 1,68 \\
\hline \multicolumn{9}{|c|}{$3^{\text {a }}$ SÉRIE ENSINO MÉDIO } \\
\hline Norte & $-0,019$ & $-4,55^{*}$ & $-0,002$ & $-0,39$ & $-0,007$ & $-1,72$ & 0,005 & 1,25 \\
\hline Nordeste & $-0,013$ & $-5,76 *$ & 0,014 & $6,54 *$ & 0,006 & $2,46^{*}$ & 0,017 & $7,79 *$ \\
\hline Centro-Oeste & $-0,045$ & $-10,08^{*}$ & $-0,008$ & $-2,35^{*}$ & $-0,022$ & $-4,87^{*}$ & 0,001 & 0,37 \\
\hline Sudeste & $-0,033$ & $-18,71^{*}$ & 0,001 & 0,4 & $-0,012$ & $-7,14^{*}$ & 0,008 & $5,38 *$ \\
\hline Sul & $-0,033$ & $-8,63^{*}$ & $-0,007$ & $-2,40 *$ & $-0,108$ & $-2,80 *$ & 0,002 & 0,5 \\
\hline
\end{tabular}

Fonte: Elaboração das autoras com base nos dados do Saeb 2017 (BRASIL, 2017).

Nota: * significativo a $5 \%$.

Para alunos do $5^{\circ}$ ano do ensino fundamental, os efeitos do trabalho infantojuvenil foram significativos e negativos para homens e mulheres em ambas as proficiências, em todas as regiões, sendo o efeito relativamente maior para as mulheres e nas notas de Português. Por sua vez, no $9^{\circ}$ ano do ensino fundamental, o impacto foi negativo e significativo para as notas de Português para homens e mulheres em todas as regiões, e para as notas de Matemática para homens em todas as regiões. No entanto, o impacto foi negativo e significativo nas notas de Matemática para as mulheres apenas no Nordeste e Sudeste. Pode-se perceber que, ao contrário do $5^{\circ}$ ano do ensino fundamental, o impacto foi maior para meninos do que para meninas, principalmente nas notas de Português.

O impacto da atividade laboral para alunos do ensino médio foi negativo e maior para os homens em ambas as notas, em magnitude maior para Português, revelando o fato de que homens são mais impactados pelo trabalho, talvez por exercerem tarefas que exigem maior força física, aumentando o cansaço e a falta de atenção nas aulas, e por estarem no mercado de trabalho com mais frequência do que as mulheres. Verifica-se efeito negativo e significativo nas notas de Português para os homens em todas as regiões, com redução em torno de 4\%. No 
caso da Matemática o efeito não foi homogêneo, sendo negativo e significativo no Sudeste, Centro-Oeste e Sul, positivo e significativo no Nordeste e não significativo no Norte. Para as mulheres, por sua vez, foi negativo e significativo nas notas de Português, exceto para o Norte e Sudeste, e em Matemática foi positivo e significativo apenas para o Nordeste e Sudeste, enquanto nas demais regiões não foi significativo.

Apesar da prevalência de um efeito negativo do trabalho sobre o desempenho escolar, maior para os mais jovens e em Português, foi possível observar resultados não significativos e até positivos para os adolescentes do ensino médio, especialmente para as meninas. Segundo Bezerra (2006), o efeito negativo que o trabalho causa no desempenho escolar pode ocorrer devido ao cansaço, às horas perdidas de estudo, ao interesse maior pelo emprego e à falta de motivação para conciliar as duas atividades. Mavrokonstantis (2011) afirma que o trabalho infantojuvenil pode causar exaustão e deixar as crianças e jovens sem energia, impedindo sua capacidade de se concentrar na sala de aula ou no estudo em casa. Porém, de acordo com Cavalieri (2002), teoricamente o efeito do trabalho sobre o desempenho escolar pode ser ambíguo e vai depender de aspectos negativos, como a redução do tempo para a aprendizagem, e de aspectos positivos, como o desenvolvimento de habilidades como disciplina, responsabilidades, socialização, entre outros. Mavrokonstantis (2011, p. 17) relata que "o trabalho pode permitir que as crianças coloquem em prática as competências aprendidas na escola, solidificando os seus conhecimentos", além de que "o trabalho pode, portanto, desenvolver o ser humano e o capital psicossocial das crianças que pode melhorar seu desempenho na escola".

Ademais, o impacto mais significativo para os meninos, no final do ensino fundamental e no ensino médio, está em acordo com a literatura. Conforme o estudo de Artes e Carvalho (2010), que estimaram o impacto do trabalho na trajetória escolar de crianças entre 10 e 14 anos usando a Pnad de 2006, seria de se esperar que o trabalho afetasse mais intensamente os meninos, já que as meninas estariam inseridas em atividades que, aparentemente, melhor se adequariam às demandas escolares, em razão principalmente da flexibilidade de horários. Assim, o trabalho prejudicaria o desempenho escolar mais intensamente para os meninos e os afazeres domésticos de forma mais sutil para as meninas.

Os resultados sugerem evidências tanto para o efeito do trabalho infantojuvenil quanto para o desempenho escolar. Verifica-se que o efeito negativo do trabalho infantojuvenil se reduz com o nível de escolaridade, sendo maior no início do fundamental para as mulheres e depois para os homens no final do fundamental e no ensino médio, além de ser maior em Português do que em Matemática, para os meninos e meninas. Porém, observa-se ainda que o desempenho escolar, tanto em Português quanto em Matemática, nos três níveis estudados, é inferior nas regiões 
Norte e Nordeste, indicando a necessidade de políticas públicas que busquem melhorar o desempenho educacional dessas regiões.

Assim, embora existam na literatura vários elementos importantes para determinar o desempenho escolar dos alunos, a avaliação de impacto empregada neste trabalho para avaliar os efeitos de trabalhar fora de casa se mostrou bastante relevante, assim como encontrado na literatura sobre essa temática, mas com outras abordagens. Nesse sentido, Andrade e Laros (2007), usando a base do Saeb de 2001 e uma análise multinível, identificaram que trabalhar fora de casa reduzia as notas de Matemática e Português de alunos da $3^{\mathrm{a}}$ série do ensino médio em torno de 1,5\%.

Já Bezerra (2006), a partir de estimativas considerando mínimos quadrados em dois estágios, encontrou que o trabalho diminuía as notas de Português e Matemática dos alunos, sendo a redução em Matemática de cerca de 10 pontos para alunos da $4^{\mathrm{a}}$ série do ensino fundamental, 8,5 para alunos da $8^{\mathrm{a}}$ série e quase 11,5 pontos para aqueles do ensino médio. Nas notas de Português, a redução era de 10 pontos para alunos da $4^{\mathrm{a}}$ série, 7 pontos para alunos da $8^{\mathrm{a}}$ série e 13 pontos para alunos do $3^{\mathrm{o}}$ ano do ensino médio. No entanto, cada hora de trabalho a mais por dia reduzia mais as notas de alunos da $4^{\mathrm{a}}$ série do ensino fundamental do que do ensino médio.

Também Emerson, Ponczek e Souza (2014), estudando o impacto do trabalho infantil em exames padronizados para o estado de São Paulo, confirmaram que trabalhar impactava negativamente o desempenho dos alunos nesses exames em Matemática e Português. Em Matemática para meninos e meninas e em Português para meninos, as estimativas foram de redução de cerca de 3\% a 3,5\% nas pontuações dos testes. Segundo os autores, no Brasil, o retorno à educação é muito alto, por isso o trabalho infantil é ineficiente no sentido de que o custo real para o indivíduo excede os benefícios. Mas eles fazem um alerta: mesmo que a aprendizagem seja prejudicada pelo trabalho infantil, ela ainda ocorre. Para o aluno, trabalhar e ir à escola é melhor do que não ir à escola e somente trabalhar.

Comparando com estudos relacionados em outros países, o trabalho de Mavrokonstantis (2011) encontrou evidência de que o trabalho infantil nas áreas urbanas do Vietnã reduz o desempenho dos alunos nas notas de Matemática de forma significativa três anos após a realização da atividade. Os alunos que trabalhavam aos 12 anos de idade tiveram as pontuações dos testes analisadas aos 15 anos. Mesmo o Vietnã não apresentando índices tão dramáticos de trabalho infantil, com quase 97\% de crianças elegíveis matriculadas na educação primária, ainda assim essa condição de trabalho está presente e gera prejuízos para o desempenho educacional dos alunos.

Destaca-se que o impacto negativo é maior e significativo para alunos do ensino fundamental quando comparados aos alunos do ensino médio, sugerindo que a atividade laboral para crianças é mais prejudicial no desempenho escolar do que 
para jovens. Mas, além disso, convém mencionar que um dos motivos para o menor impacto nos alunos do ensino médio pode ser o baixo interesse deles na realização da prova, e até mesmo o menor empenho das escolas na aplicação ao ensino médio, refletindo informações mais superficiais da realidade vivenciada. Assim, possivelmente a qualidade das informações disponíveis influencie os resultados. Outro aspecto que merece ser mencionado é abandono escolar daqueles que não têm sucesso em acompanhar a escola devido ao trabalho, o que retira da análise aqueles com menor desempenho e reduz o impacto do trabalho no desempenho escolar nessa última etapa da educação básica.

Em uma análise apenas para o ensino fundamental, Ono (2015) observou resultado semelhante sobre o impacto do trabalho no desempenho escolar com dados do Saeb de 2007 até 2011, revelando efeito negativo preocupante para alunos do $4^{\circ}$ ano do ensino fundamental, em torno de 17 pontos em Português e 13 pontos em Matemática. Se comparado com esses resultados, em 2017, o impacto negativo do trabalho infantil no desempenho foi menor, conforme mostra a Tabela 3. No entanto, esse efeito prejudicial se mantém no país e ainda carece de maiores esforços por parte das políticas públicas voltadas especialmente à erradicação do trabalho infantil, notadamente nas regiões menos desenvolvidas, onde o desempenho escolar é menor.

Assim, o presente estudo contribui com a literatura sobre a temática ao verificar que o trabalho infantojuvenil ainda tem impacto negativo principalmente nas notas de Português e para estudantes do ensino fundamental. Além disso, alunas do $5^{\circ}$ ano do ensino fundamental eram mais prejudicadas, ao passo que no $9^{\circ}$ ano do ensino fundamental e na $3^{\mathrm{a}}$ série do ensino médio os meninos eram mais afetados negativamente. O maior impacto para os mais jovens pode acarretar atraso e abandono escolar, o que representaria menos anos de estudos, além da menor qualidade daqueles cursados. Nesse sentido, ressalta-se a importância das políticas públicas para que o trabalho infantojuvenil seja minimizado, a fim de reduzir os problemas no desempenho escolar, pois também poderá haver reflexos futuramente, na vida adulta, decorrentes dos menores retornos ao capital humano.

\section{CONSIDERAÇÕES FINAIS}

Este artigo teve como objetivo avaliar o impacto do trabalho de crianças e adolescentes no desempenho escolar. Para isso foram utilizadas informações da Prova Brasil/Aneb fornecidas pelo Saeb de 2017, empregando as notas de proficiência em testes de Português e Matemática como variáveis de resultado. A premissa é de que o tempo disponível para uma criança ou adolescente é dividido entre lazer, educação e trabalho. Dessa forma, se o tempo dedicado ao trabalho é positivo, as atividades 
de lazer e educação podem ficar prejudicadas, o que também pode impactar o rendimento escolar.

Foram feitas estratificações para as três séries de alunos disponíveis na base de dados, do $5^{\circ}$ e $9^{\circ}$ anos do ensino fundamental e da $3^{\mathrm{a}}$ série do ensino médio, além de uma análise das heterogeneidades regionais. Como estratégia de estimação utilizou-se o Propensity Score Matching, que constitui uma metodologia de avaliação de impacto, contornando o problema do viés de seleção presente nas abordagens tradicionais, a partir da análise de grupos de tratamento e de controle, obtidos por meio de técnicas de pareamento, imitando um processo de seleção aleatória. Foram utilizadas cinco técnicas de pareamento para garantir a robustez da análise, além de vários testes para as condições de balanceamento dos grupos de tratamento e controle, embora apresentados os resultados apenas para o pareamento tipo raio.

$\mathrm{Na}$ estratificação por região geográfica, em todas as séries analisadas, percebeu-se que o impacto do trabalho no desempenho escolar em Português e Matemática foi negativo e significativo. Para o $5^{\circ}$ ano do ensino fundamental, o trabalho reduziu as notas de Português em média 11,7\%, e de Matemática em média 8,5\%. No $9^{\circ}$ ano do ensino fundamental, o impacto negativo foi de, em média, 3,5\% para notas de Português e 1,6\% para as de Matemática. Já no ensino médio, o impacto médio negativo do trabalho foi de $2 \%$ nas notas de Português e de $1,2 \%$ nas de Matemática.

Em todas as séries e regiões geográficas analisadas, o trabalho afetava mais negativamente as notas de Português do que as de Matemática. Inferiu-se que isso se deve ao fato de que a disciplina de Língua Portuguesa requer maior atenção e concentração dos alunos, sendo afetada em maior magnitude pela atividade laboral. Também se percebeu que o impacto do trabalho sobre o desempenho escolar de crianças do $5^{\circ}$ ano do ensino fundamental foi de magnitude maior do que as outras séries analisadas, indicando que o trabalho de crianças é mais prejudicial. Além disso, confirma o fato de que o trabalho para jovens e adolescentes estudantes do ensino médio muitas vezes é menos prejudicial para o desempenho escolar do que para o trabalho de crianças, sendo que em algumas regiões o impacto foi até mesmo positivo.

Também foi feita estratificação por gênero e localização geográfica, dividindo os alunos das séries em homens e mulheres. Para alunos do $5^{\circ}$ ano do ensino fundamental, os efeitos do trabalho infantojuvenil foram significativos e negativos para homens e mulheres em ambas as proficiências em todas as regiões, sendo o efeito relativamente maior para as mulheres nas notas de Português. No $9^{\circ}$ ano do ensino fundamental, o impacto foi negativo e significativo para homens e mulheres nas notas de Português e para homens nas notas de Matemática em todas as regiões. Para as mulheres nas notas de Português, o impacto negativo 
do trabalho foi encontrado apenas nas regiões Nordeste e Sudeste. Ao contrário do $5^{\circ}$ ano do ensino fundamental, o impacto foi maior para meninos do que para meninas, principalmente nas notas de Português. Já para alunos do ensino médio, o impacto da atividade laboral foi negativo e significativo nas notas de Português e Matemática para os homens em todas as regiões, e para as mulheres apenas em algumas regiões, sendo o efeito negativo maior para os homens em ambas as notas. Em relação às regiões, o efeito negativo do trabalho infantojuvenil segue o comportamento observado para o Brasil, não confirmando a hipótese de que regiões mais pobres tenderiam a ser mais impactadas pela atividade laboral. Não obstante, verificou-se que o desempenho escolar é inferior no Norte e Nordeste, em Português e Matemática, nos três níveis estudados.

Este trabalho inovou ao utilizar uma base de dados bastante recente e considerar como controles para a probabilidade de o aluno trabalhar fora do ambiente familiar características não só dos alunos e de suas famílias, mas também da escola e dos professores. Sendo assim, ressalta-se que os resultados seriam muito mais elevados caso esses controles adicionais não fossem utilizados, indicando a robustez da pesquisa. Salienta-se que este artigo não pretende esgotar as discussões a respeito dos impactos do trabalho infantojuvenil, mas contribuir para essa literatura.

Como é comum em estudos científicos dessa natureza, algumas limitações e dificuldades foram encontradas. Primeiramente a inexistência de uma variável sobre renda no questionário do Saeb forçou a criação de uma proxy. Em segundo lugar, os questionários socioeconômicos utilizados foram respondidos pelos próprios alunos, podendo haver omissão de variáveis e respostas incorretas e inverídicas. Além disso, é importante mencionar que o impacto do trabalho no desempenho escolar poderia ser ainda maior do que o encontrado. Muitos alunos que não conseguem conciliar os estudos com o trabalho abandonam a escola, e nesse sentido não são incluídos na análise. Ademais, as informações disponíveis eram de 2017, sendo necessárias atualizações quando informações mais atuais estiverem disponíveis.

De forma geral, o trabalho fora de casa não é o único fator que pode ser responsável pelo fraco desempenho escolar dos alunos. No entanto, conforme se verificou nesta pesquisa, constitui-se em elemento importante, pois afetou negativamente o rendimento dos alunos da amostra Saeb de 2017, embora em intensidades variadas conforme a série frequentada pelo aluno, região geográfica e gênero.

Portanto, apesar de os resultados da pesquisa apontarem que as magnitudes de impacto do trabalho infantojuvenil não são homogêneas para o desempenho escolar, foi possível verificar que, de modo geral, esse efeito ainda é negativo e significativo, sobretudo para as crianças no ensino fundamental. Nesse sentido, esses resultados sugerem que ainda há a necessidade de se ampliarem as políticas públicas tanto buscando um sistema educacional de melhor qualidade quanto amenizando 


\section{as desigualdades de renda e sociais, de tal forma que especialmente o trabalho de crianças, as quais se mostraram mais prejudicadas, seja reduzido no país.}

\section{REFERÊNCIAS}

ALVES-MAZZOTTI, A. J. Repensando algumas questões sobre o trabalho infanto-juvenil. Revista Brasileira de Educação, Rio de Janeiro, n. 19, p. 87-98, 2002.

ANDRADE, J. M.; LAROS, J. A. Fatores associados ao desempenho escolar: estudo multinível com dados do SAEB/2001. Psicologia: teoria e pesquisa, Brasília, DF, v. 23, n. 1, p. 33-42, 2007.

ARTES, A. C. A.; CARVALHO, M. P. O trabalho como fator determinante da defasagem escolar dos meninos no Brasil: mito ou realidade? Cadernos Pagu, Campinas, SP, n. 34, p. 41-74, 2010.

BARROS, R. P.; MENDONÇA, R.; SANTOS, D. D. dos; QUINTAES, G. Determinantes do desempenho educacional no Brasil. Pesquisa e Planejamento Econômico, Rio de Janeiro, v. 31, n. 1, p. 1-42, 2001.

BEZERRA, M. E. G. O trabalho infantil afeta o desempenho escolar no Brasil? 2006. Dissertação (Mestrado em Economia Aplicada) - Universidade de São Paulo, São Paulo, 2006.

BEZERRA, M. E.; KASSOUF, A. L.; ARENDS-KUENNING, M. The impact of child labor and school quality on academic achievement in Brazil. Bonn, Germany: IZA - Institute of Labor Economics, 2009. (Discussion Papers, n. 4062).

BRASIL. Senado Federal. Constituição (1988). Constituição daRepública Federativa do Brasil. Brasília, DF, 1988. Disponível em: http://www.planalto.gov.br/CCivil_03/Constituicao/Constituicao. htm. Acesso em: 29 nov. 2018.

BRASIL. Presidência da República. Lei n. 8069, de 13 de julho de 1990. Dispõe sobre o Estatuto da Criança e do Adolescente. Brasília, DF, 1990. Disponível em: http://www.planalto.gov.br/ccivil_03/ LEIS/L8069.htm. Acesso em: 29 nov. 2018.

BRASL. Instituto Nacional de Estudos e Pesquisas Educacionais Anísio Teixeira. Qualidade da educação: uma nova leitura do desempenho dos estudantes da $8^{a}$ série do ensino fundamental. Brasília, DF: Inep, 2003.

BRASIL. Instituto Brasileiro de Geografia e Estatística. PNAD - Pesquisa Nacional por Amostra de Domicílios. Rio de Janeiro, 2015. Disponível em: https:/www.ibge.gov.br/estatisticas/sociais/ rendimento-despesa-e-consumo/9127-pesquisa-nacional-por-amostra-de-domicilios.html?=\&t=oque-e. Acesso em: set. 2021.

BRASIL. Instituto Nacional de Estudos e Pesquisas Educacionais Anísio Teixeira. SAEB - Sistema de Avaliação da Educação Básica. Brasília, DF: Inep, 2017.

CALIENDO, M.; KOPEINIG, S. Some practical guidance for the implementation of propensity score matching. Journal of Economic Surveys, v. 22, n. 1, p. 31-72, 2008.

CAVALIERI, C. H. O impacto do trabalho infantil sobre o desempenho escolar: uma avaliação para o Brasil metropolitano. 2002. Tese (Doutorado em Economia de Empresas) - Fundação Getúlio Vargas, São Paulo, 2002. 
COLOMBO, D. K. Trabalho infantil e proficiência escolar: um estudo com dados em painel. 2012. Dissertação (Mestrado em Economia) - Escola de Economia de São Paulo, Fundação Getúlio Vargas, São Paulo, 2012.

EMERSON, P. M.; PONCZEK, V.; SOUZA, A. P. Trabalho infantil e aprendizagem. Banco Mundial, 2014.

GREENE, W. H. Econometric Analysis. 8. ed. New York: Pearson, 2018.

JACINTO, P. de A.; RODEGHIERO, L. B. Retorno em escolaridade: um estudo para a região metropolitana de Porto Alegre. Revista Brasileira de Estudos Regionais e Urbanos, Curitiba, v. 6, n. 1, p. 37-56, 2012.

KASSOUF, A. L. O que conhecemos sobre o trabalho infantil? Nova Economia, Belo Horizonte, v. 17, n. 2, p. 323-350, 2007.

KHANDKER, S. R.; KOOLWAL, G. B.; SAMAD, H. A. Handbook on impact evaluation: quantitative methods and practices. The World Bank, 2009.

MAVROKONSTANTIS, P. The impact of child labour on educational attainment: evidence from Vietnam. Oxford, UK: University of Oxford, 2011. (Young Lives Student Paper).

MENEZES-FILHO, N. A. Os determinantes do desempenho escolar do Brasil. São Paulo: Instituto Futuro Brasil, 2007.

ONO, I. B. O impacto do trabalho infantil no desempenho escolar. 2015. Dissertação (Mestrado em Economia Aplicada) - Universidade de São Paulo, São Paulo, 2015.

PUTNICK, D. L.; BORNSTEIN, M. H. Is child labor a barrier to school enrollment in low-and middle-income countries? International Journal of Educational Development, v. 41, p. 112-120, 2015.

ROSATI, F. C.; ROSSI, M. Children's working hours and school enrollment: evidence from Pakistan and Nicaragua. The World Bank Economic Review, v. 17, n. 2, p. 283-295, 2003.

ROSENBAUM, P. R.; RUBIN, D. B. Assessing sensitivity to an unobserved binary covariate in an observational study with binary outcome. Journal of the Royal Statistical Society, v. 45, n. 2, p. 212-218, 1983.

SCHWARTZMAN, S.; SCHWARTZMAN, F. Trabalho infantil no Brasil. Brasília, DF: OIT, 2004.

\section{COMO CITAR ESTE ARTIGO}

MATTEI, Taíse Fátima; CUNHA, Marina Silva da. Impacto do trabalho infantojuvenil no desempenho escolar para o Brasil urbano. Estudos em Avaliação Educacional, São Paulo, v. 32, e07159, 2021. DOI: https://doi.org/10.18222/eae.v32.7159

Recebido em: 26 FEVEREIRO 2020

Aprovado para publicação em: 1 JUNHO 2021

Este é um artigo de acesso aberto distribuído nos termos da licença Creative Commons do tipo BY-NC. 